\title{
O que pode o ensino de história? Sobre o uso de fontes na sala de aula
}

Nilton Mullet Pereira Fernando Seffner

\begin{abstract}
R esumo: 0 artigo discutea utilização de fontes históricas na sala de aula da E scola Básica. Trata dos efeitos e, ao mesmo tempo, da incorporação, por parte da sala de aula, de um dos fenômenos mais importantes da historiografia contemporânea, a chamada "revolução documental". A preocupação dos autores é discutir como a história ensinada pode inserir-se no movimento de "crítica ao documento"; pensar e propor alternativas pedagógicas que incluam a possibilidade de usar, no cotidiano da sala de aula de história, as mesmas fontes com as quais os pesquisadores criam relatos sobreo passado, procurando dar um estatuto teórico à discussão do uso de fontes para ensinar história a estuda0ntes do ensino fundamental e médio. Partimos da suposição de que o uso de fontes no ensino de história pode ser uma estratégia adequada e produtiva para ensinar história a indivíduos que não têm como objetivo se tornar historiadores, mas para os quais o conhecimento da história pode fazer muita diferença na compreensão do mundo em que vivem.

Palavras-chave: H istória. E nsino. Fontes. D ocumento.
\end{abstract}

\footnotetext{
* Professor D outor N ilton M ullet Pereira. Professor O rientador deE stágios D ocentes em H istória, FACED / UFRG S. E-mail: niltonmp.pead@ gmail.com.

* Professor D outor Fernando Seffner. Professor O rientador de E stágios D ocentes em H istória, FACED / UFRG S. E-mail: fernandoseffner@gmail.com.
} 
O que pode o ensino de história?...

\section{Introdução}

A pesquisa histórica, a história ensinada na academia e o ensino de história na escola básica possuem tempos e modos de produção e transmissão bastante singulares e próprios, portanto, distintos. Entretanto, não decorre dessa afirmação um elogio à cisão entre a pesquisa e o ensino ou entre a escola e a universidade. A o contrário, o reconhecimento da especificidade de cada uma dessas histórias em cada um destes lugares pode bem permitir uma comunicação mais fecunda entre elas. Conhecer as particularidades de cada campo, para melhor propor relações entre eles: eis nossa proposição.

0 objeto deste artigo não se resume, então, à constatação da especificidade dessas histórias, mas parte de tal constatação a fim de tratar do compasso e do descompasso entre a historiografia e 0 ensino de história na escola básica. Particularmente, este artigo trata dos efeitos e, ao mesmo tempo, da incorporação, por parte da sala de aula, de um dos fenômenos mais importantes da historiografia contemporânea, a chamada "revolução documental".

A ssim, nossa preocupação é discutir como a história ensinada pode inserir-se no movimento da "crítica ao documento"; é pensar e propor alternativas pedagógicas que incluam a possibilidade de usar, no cotidiano da sala de aula de história do ensino fundamental e médio, as mesmas fontes com as quais os pesquisadores criam relatos sobre o passado. Partimos da suposição de que o uso de fontes no ensino de história pode ser uma estratégia adequada e produtiva para ensinar história a indivíduos que não tem como objetivo se tornar historiadores, mas para os quais o conhecimento da história pode fazer muita diferença na compreensão do mundo em que vivem e, portanto, na construção de seus projetos de vida.

\section{A revolução documental ea sala de aula}

Os propósitos que movem este ensaio, acima explicitados, sustentam-se em duas problematizações: uma diz respeito ao longo 
processo de redefinição do conceito de fonte histórica; outra se refere à maneira como a sala de aula de história tem incorporado os avanços da historiografia, em estreita conexão com um conjunto de outras modificações pelas quais passa a escola atualmente. Vamos tratar um pouco de cada uma dessas problematizações.

D e um modo decidido desde o início da chamada E scola dos A nais, ${ }^{1}$ mas já bem antes, o conceito de fonte histórica tem se ampliado e se transformado significativamente. Por um lado, a revolução documental acabou com o império do documento escrito, permitindo que o olhar do historiador se desviasse dos documentos oficiais e das tramas políticas, típicas da história positivista, para uma quantidade indefinível e enorme de vestígios do passado: imagens, filmes, crônicas, relatos de viagem, registros paroquiais, obras de arte, vestígios arquitetônicos, memória oral... Mas, principalmente, a revolução documental dobrou o olhar da disciplina H istória para aspectos da vida social, antes distantes do olhar dos historiadores, e apenas abordados por determinadas ciências como a Antropologia e a E tnologia. 0 imaginário, as mentalidades, 0 cotidiano, a vida privada, sensibilidades passam a fazer parte do universo da $\mathrm{H}$ istória e permitem aos historiadores montar uma trama mais bela da vida dos povos e dos tempos passados. Também permite abandonar a velha história eurocêntrica e abordar a história dos povos africanos e indígenas, que outrora eram objetos de estudo quase exclusivos da Antropologia.

Por outro lado, junto a essa revolução quantitativa, a revolução documental foi acompanhada por uma forte crítica ao conceito de documento. A partir da perspectiva dos novos historiadores (LE G OFF, 2005) e, sobretudo, em função da contribuição de Michel Foucault (1987), o documento se torna monumento, ou seja, ele é rastro deixado pelo passado, construído intencionalmente pelos homens e pelas circunstâncias históricas das gerações anteriores. 0 documento não é mais a encarnação da verdade, nem mesmo pode ser considerado simplesmente "verdadeiro" ou "falso". 0 ofício do historiador deixa de ser 0 de cotejar o documento para 
verificar sua veracidade, e passa de ser o de marcar as condições políticas da sua produção. 0 documento/ monumento é um engenho político, é um instrumento do poder e, ao mesmo tempo, uma manifestação dele.

Os documentos são monumentos que as gerações anteriores deixaram. E les são construções a partir de onde os homens procuraram imprimir uma imagem de si mesmos para as gerações futuras. D esde o início, eles são monumentos construídos, nunca rastros deixados ao acaso de modo acidental. A demais, o que os historiadores têm a sua disposição não é o passado, mas apenas uma seleção efetuada no interior de jogos de forças, sempre atualizados pelas gerações que nos precederam e, ainda, pelas circunstâncias do presente. 0 u seja, o que sobrevive do passado, como diz L eG off (2003, p. 525), é "escolha efetuada quer pelas forças que operam no desenvolvimento temporal do mundo e da humanidade, quer pelos que se dedicam à ciência do passado e do tempo que passa, os historiadores". A inda no presente, os historiadores realizam uma seleção dos vestígios que o tempo deixou. Seleção esta que molda novamente as séries de documentos e os quadros que procuram ordenar o movimento de um tempo anterior, segundo os métodos e as teorias criadas no presente. M ais uma vez, a nossa geração se põe a intervir nos vestígios do passado. D epois de uma longa e intensa intervenção, deixamos para a geração seguinte temas, objetos, vestígios das sociedades que nos antecederam, mas que dizem sobre nós mesmos e marcam o lugar que tivemos nesse movimento ininterrupto de criar e recriar 0 que somos. Anunciamos aqui uma possibilidade de relação com 0 ensino de história: 0 trabalho em sala de aula com documentos pode ser pensado nesta ótica de criar e recriar o que somos, dando um sentido original para 0 ensino de história, em conexão com a formação da identidade dos alunos, situados em um determinado contexto histórico, que necessita ser entendido.

0 triunfo do documento deixou de ser o triunfo da verdade. 0 critério de verdade empirista, baseado na idéia de uma correspondência entre o relato e a realidade, foi abandonado pela história 
desde a crítica ao positivismo, para o qual os documentos eram veículos da verdade do passado. A o contrário, o critério da correspondência passou a ser inaplicável à pesquisa histórica, sobretudo porque aprendemos a distinguir passado e história (JE NK IN S, 2004). 0 passado é o objeto de estudo do historiador, apenas acessível pela linguagem que o ordena; a história é um discurso que os historiadores produzem como resultado de um longo trabalho de seleção de fontes, de seleção do método e de seleção da teoria, merguIhado em importantes conflitos e lutas políticas do presente. A produção da verdade em história tornou-se um engenho complexo. Ao invés de se mostrar como um trabalho recalcado, de quem quer acessar um passado do qual poderia apenas aproximar-se, a produção da verdade se tornou uma produção discursiva. I sso implicou reconhecer que a ciência histórica, para se efetivar, precisa considerar toda uma série de mediações, desde o caráter do documento como monumento, até a compreensão da história como um discurso sobre o passado, política e culturalmente informado.

E sse debate passa ainda pelo tratamento do discurso histórico como um conjunto de representações (CH ARTIE R, 1991) sobre o passado. Assim, entendemos que o discurso histórico disputa espaço com outras representações acerca do passado que transitam na nossa sociedade, como aquelas produzidas pela literatura, pelo cinema, pela televisão, pelo rádio, pelas propagandas comemorativas oficiais do governo ou das empresas etc. $N$ a memória social, o passado se constrói num jogo de forças constante e no seu interior a história é um dos discursos que procura marcar lembranças e determinar esquecimentos. É assim que ocorre quando os estudantes da E scola Básica assistem a uma minissérie televisiva como 0 Q uinto dos Iinfernos, ${ }^{2}$ por exemplo. E les são colocados diante de representações que ensinam sobre o passado e produzem memória, tanto quanto ou mais do que a aula de $\mathrm{H}$ istória. 
O que pode o ensino de história?...

\section{Sobre os objetivos do ensino de história}

0 tempo da disciplina escolar aproxima-se mais do conjunto de representações do senso comum do que do tempo da pesquisa. I sso quer dizer que a incorporação dos avanços da historiografia pela sala de aula tem a ver tanto com a cultura específica do espaço escolar, quanto com o descompasso e a distância existente entre a pesquisa e o ensino. 0 que se ensina na escola não é o mesmo que se ensina na academia, e nem poderia ser. I sso se explica por duas ordens de fatores: os processos de mediação didática que buscam construir o conhecimento escolar, a partir de várias fontes, sendo uma delas o conhecimento produzido pela pesquisa histórica; e os interesses, circunstâncias socioculturais específicas e contexto político específico daqueles que são os receptores da história ensinada na escola, alunos e comunidade de pais e professores.

$\mathrm{No}$ curso de $\mathrm{H}$ istória, integrado ao ambiente acadêmico, o ensino se volta a uma formação que exige a aprendizagem da filosofia e da epistemologia da disciplina, de modo que não apenas o futuro professor de H istória amplie e refine seu olhar para o real, mas que se torne um agente da pesquisa e da socialização do conhecimento histórico. $\mathrm{N}$ a escola, os objetivos e procedimentos são aqueles definidos em diversos níveis, todos eles fortemente políticos. A H istória é disciplina escolar citada na Constituição Federal de 1988 (como de resto, citada em todas as constituições), e de modo explícito na LDB. ${ }^{3} \mathrm{~A}$ Constituição Federal cita duas áreas apenas ao falar da educação nacional: ensino de língua materna e ensino de história. $\mathrm{Na}$ LD B, a disciplina de $\mathrm{H}$ istória aparece com destaque, e no parágrafo 40 do A rtigo 26 se diz claramente que "o ensino da $H$ istória do Brasil levará em conta as contribuições das diferentes culturas e etnias para a formação do povo brasileiro, especialmente das matrizes indígenas, africana e européia". D ecretos federais já trataram de inserir temas no ensino escolar de H istória, notadamente as questões ligadas à identidade negra e indígena. ${ }^{4} \mathrm{D}$ esta forma, 
verifica-se que os processos que determinam o estabelecimento de objetivos para o ensino de H istória na escola pública brasileira são bastante diversos daqueles que regem o ensino superior.

N ossa concepção é que ensinar história na escola significa permitir aos estudantes abordar a historicidade das suas determinações socio-culturais, fundamento de uma compreensão desi mesmos como agentes históricos e das suas identidades como construções do tempo histórico. 0 presente, que é o espaço/tempo dos estudantes, de onde eles olham para si mesmos e para o passado, torna-se histórico, na medida em que, passo a passo, o professor de $\mathrm{H}$ istória consegue historicizar as instituições, as políticas, os modelos culturais, os modos de ser e, sobretudo, as identidades. Trata-se de levar as novas gerações a conhecerem suas próprias determinações, a construir relações de pertencimento a um grupo, a uma história coletiva e a lutas coletivas.

$\mathrm{N}$ a escola, 0 ensino de história coloca os estudantes diante das representações que as gerações passadas produziram sobre si mesmas (nossas fontes) e, ao mesmo tempo, estimula-os a elaborar a crítica das representações que hoje produzimos sobre nosso próprio passado. E ntão, ao ensinarmos história na escola, pomos-nos a ensinar a ler o passado através das representações que sobre o passado estão sendo ou foram produzidas, mas também, quem sabe, através dos vestígios deixados pelas gerações anteriores.

0 ensino de história procura mostrar que a disciplina é um discurso que, em meio a diversos outros e em conflito com estes, cria ordem para o passado, estabelece formas de sentir e de olhar para 0 último e, com isso, situa o sujeito num certo presente. 0 professor de H istória na escola estabelece as diferenças entre os diversos discursos que se propõem a recriar o passado e o relato historiográfico, discute a especificidade do cinema, da televisão, da literatura e, sobretudo, da historiografia como o espaço mesmo do ofício da produção de representações sobre o passado.

0 alvo principal do ensino de história na escola é a construção da compreensão de que estudar esta disciplina é uma ação social 
que se dá no presente. A dedicação ao estudo da história na escola não consiste em mero diletantismo, mas em compreender asi mesmo e a sua sociedade e, sobretudo, acumular conceitos para ler a própria realidade, e criar novidades, formas novas de intervenção na sociedade, novas práticas sociais, novas realidades. E m última análise, 0 ensino de história deve levar homens e mulheres do meio urbano ou rural a se tornarem artífices de si mesmos, a construírem-se como singularidades e a olhar para seu presente como diferença em relação ao seu passado e, ao mesmo tempo, como produto dos conflitos e das lutas do passado.

$\mathrm{N}$ a base desses objetivos, está o pressuposto de que a escola forma cidadãos, não historiadores. Forma sujeitos capazes de historicizar a própria vida e de, como conseqüência, promover rupturas e pôr em suas mãos os destinos da sua cidade, da comunidade, da região. 0 acúmulo de conceitos históricos serve para tornar os estudantes sujeitos capazes de produzir opiniões e de considerar soluções políticas para os problemas do seu tempo.

Os objetivos descritos acima servem para marcar a especificidade da história ensinada na escola. Isso deve levar os professores a refletirem sobre como 0 trabalho com as fontes pode auxiliar a alcançar os referidos objetivos. Também esses objetivos procuram afirmar, a partir da especificidade dos espaços de ensino e de pesquisa em história, a aproximação entre os avanços da historiografia e a sala de aula de H istória.

Já afirmamos que a sala de aula de $\mathrm{H}$ istória está muito mais suscetível à memória coletiva e aos discursos sobre o passado veiculados pela grande mídia, do que o espaço das aulas de graduação em H istória que, por si mesmas, são lugares privilegiados da crítica das representações que são produzidas sobre o passado.

As noções sobre história que transitam no senso comum reproduzem modos de estudar história, de reconhecer o papel da disciplina História no currículo escolar e de, inclusive, produzir material didático para 0 ensino. 0 s próprios professores de $\mathrm{H}$ istória, não apenas os estudantes, estão, em boa parte dos casos, mergulhados 
em representações da realidade atual e do passado, que transitam na memória coletiva e que não são resultado da análise histórica.

A escola e a sala de aula de $\mathrm{H}$ istória em particular vivem num tempo em que as circunstâncias sociais que limitam a produção do conhecimento são muito mais percebidas, desde os problemas do escasso tempo de estudo que possui a maioria dos professores, devido principalmente às grandes jornadas de trabalho, até a necessidade quase impositiva do uso do livro didático. Essas circunstâncias ensejam que a sala de aula se baseie em representações sobre o passado, cristalizadas no senso comum e, conseqüentemente, distancie-se dos avanços da historiografia. Sendo assim, a aula de $\mathrm{H}$ istória na escola básica tem poucas possibilidades de conseguir inserir novos conteúdos, resultados de pesquisas mais recentes, novos métodos de pesquisa e as novas tendências teóricas e epistemológicas da história.

A distância entre a sala de aula da escola básica, a pesquisa histórica e a sala de aula dos cursos de graduação em $\mathrm{H}$ istória se deve a uma distinção de natureza. $\mathrm{O}$ u seja, cada um destes espaços possui temporalidades distintas e finalidades específicas. Reafirmamos que, no caso da escola, temos um contato mais íntimo com as representações da memória coletiva, isso tanto em função de os estudantes estarem, obviamente, mergulhados nela, quanto ao fato de que os professores, por razões diversas, igualmente, em boa parte, estarem mais suscetíveis a ela do que à pesquisa histórica e às novidades da historiografia.

\section{As fontes na sala de aula de H istória}

U ma das representações cristalizadas que referimos acima diz respeito, justamente, ao papel das fontes na produção do conhecimento histórico e seu uso na sala de aula, e é sobre esse tema que tratamos a seguir. 
0 critério de verdade que, por longo tempo, fora utilizado pela história tradicional e que ainda é predominante no cotidiano da nossa sociedade é o da correspondência entre o relato e o fato. Vez por outra, os professores de H istória se vêem compelidos a cair na armadilha da teoria da correspondência, ${ }^{5}$ na vã tentativa de oferecer à $\mathrm{H}$ istória a mesma objetividade que concedem às chamadas A ciências naturais.

0 fato do objeto de ensino dos professores estar, na maioria das vezes, distante no tempo e no espaço, cria uma série de constrangimentos, sobretudo, para aqueles ainda demasiado investidos do sonho de uma identificação da escrita da história com um passado que realmente teria ocorrido. Sem dúvida, não é um engenho fácil ensinar para as crianças do ensino fundamental que o texto que escrevemos como a história de um determinado grupo ou cultura, pode ter sido escrito e significado de outro modo pelos personagens desse grupo ou cultura que inserimos na nossa trama.

É nesse contexto de dificuldades epistemológicas que se inclui o problema do uso das fontes em sala de aula, via de regra, utilizadas como prova e ilustração dos argumentos e descrições escritas, decorrência de uma ânsia em dar realidade ao relato histórico. U m bom exemplo disso pode ser visto numa aula de história na qual o professor afirma as punições definidas para a A lemanha como decorrência da derrota na Primeira G uerra M undial e, em seguida, mostra artigos do Tratado de Versalhes que corroboram suas afirmações. 0 problema não é o fato de o professor levar o referido documento para a sala de aula, mas utilizar a fonte para confirmar o que mencionou sobre o final da G uerra, procedimento que define o caráter de prova do documento e o caráter submisso do relato à fonte. Ao invés disso, o professor poderia problematizar o Tratado de Versalhes, quanto ao papel que desempenhou na época em que foi criado como um monumento.

O utro exemplo interessante são as imagens dos monges copistas, ${ }^{6}$ que servem para mostrar que a I greja teria conservado, através de um trabalho minucioso e paciente, o conhecimento da 
civilização clássica. Q uando utilizadas como prova para mostrar ações da I greja na I dade M édia, essas imagens simplesmente deixam de ser consideradas como monumentos e a aula de história perde uma boa oportunidade de discutir o papel constitutivo das imagens constantes nas publicações didáticas e de perceber 0 olhar que os livros didáticos direcionam para o medievo quando lançam mão dessas imagens. $\mathrm{O}$ u seja, perde-se de ensinar às crianças o papel que as fontes assumem no interior de cada geração e de cada uso que delas se faz. N este caso, parece-nos que tais imagens têm servido para, de maneira bastante velada, mostrar que o perío do medieval não passou de um intervalo obscuro na civilização e que o seu legado cultural não passou de cópia de tudo o que se produzira no mundo antigo clássico.

A conseqüência disso é a compreensão de que, se não podemos utilizar experiências, tal como a Física ou a Química, ou mesmo construir fórmulas lógicas e coerentes como a M atemática, nossa solução é provar o que dizemos a partir das fontes. Pensar ou mesmo fazer isso quer dizer assumir que a verdade da história não está no relato, mas nas fontes, tal como o percebiam os positivistas. A inda hoje, os espectros do positivismo parecem guiar a prática de muitas salas de aula de $\mathrm{H}$ istória, não como produto de uma ciência ou de uma filosofia da história, mas pela via de uma memória coletiva e do senso comum.

D iante dessas dificuldades, gostaríamos de fazer uma advertência de ordem pedagógica em relação ao uso das fontes em sala de aula: não podemos pensar que há uma determinação da natureza para que se utilizem fontes na aula de história. I sso quer dizer que não queremos sucumbir à obrigação de usar documentos na sala de aula. Parece que, nos últimos tempos, a utilização de fontes no ensino de $\mathrm{H}$ istória se tornou algo inquestionável, moderno, avançado e de acordo com as últimas tendências historiográficas e educacionais. 0 que gostaríamos de argumentar é que o uso de fontes no ensino de H istória na escolabásica decorrenão deuma obrigação transcendental, mas de uma disposição teórica pedagógica do professor. Portanto, 
O que pode o ensino de história?...

não utilizar as fontes como parte de um procedimento pedagógico também é uma alternativa.

A idéia fixa de que a fonte deve ser usada em sala de aula leva professores a utilizá-la sem perguntar sobre os fundamentos e as implicações teóricas dessa utilização. $\mathrm{N}$ a escola, as novas tendências pedagógicas jamais se apresentam como problemas teóricos, mas como rápidas soluções cotidianas para o velho problema de tornar a aula de H istória mais atraente para os estudantes, de maneira que estes não declarem, como o fazem seguidamente, que história não serve para nada e que a aula de $\mathrm{H}$ istória é demasiado chata.

0 questionamento que movimenta este texto é "como fundamentar o uso das fontes no ensino de história?" ou, por outra, "como o uso das fontes utilizadas pelos historiadores para a pesquisa pode se revelar como suporte pedagógico para o ensino"?

I niciamos a responder as perguntas acima com outras perguntas: ao usar as fontes, para que as usamos: para comprovar, através dos documentos, as asserções que fazemos? Para oferecer ao aluno uma prova da existência do passado? Para instigar o estudante a gostar da aula de $\mathrm{H}$ istória? Para mostrar ao aluno que o seu professor fala a verdade, mas que sua fala somente pode ser reconhecida frente a uma fonte viva do passado? Para provar às novas gerações que a história é uma ciência séria e que tudo que se diz sobre 0 passado não é mero diletantismo? Para permitir que as crianças e os adolescentes possam entender os caminhos da pesquisa histórica, de modo a se darem conta de como a construção do conhecimento histórico é uma atividade complexa? Para responder a incômoda pergunta das crianças: como você sabe isso se não estava lá?

E stas perguntas poderiam continuar indefinidamente sendo listadas; as justificativas são inúmeras, algumas deveras semelhantes. D esse modo, gostaríamos de reduzi-las às duas últimas e problematizar cada uma delas. Iniciemos pela última.

Justificar a utilização das fontes históricas em sala de aula para responder a indagação infantil "como você sabe se não estava lá" não é outra coisa senão sucumbir ao critério de verdade da 
criança; não é outra coisa que assumir um fantasma de todas as horas: a vã tentativa de coincidir relato e realidade. Esse critério de verdade já não tem lugar no âmbito da produção historiográfica.

A coincidência entre passado e história é um subproduto da memória coletiva, um dado do senso comum, que não cessa de se reproduzir e que, por isso mesmo, causa embaraço aos professores, pois tende a fazer perceber que o relato histórico possa ser cópia do passado ou que o passado possa ser restituído tal qual ocorreu, pela trama escrita pelos pesquisadores. Essa situação embaraçosa é mais um problema da disciplina escolar do que da pesquisa que, há muito, já deixou de considerar essa questão um problema.

A resposta apressada para resolver o problema colocado pelo estudante leva, na contramão da historiografia e da epistemologia da H istória, a preencher o espaço da sala de aula com fontes, sobretudo com documentos que narram exatamente o mesmo objeto de que fala o professor (sejam leis, tratados, crônicas, imagens, mapas etc.). E ste afirma, sem a intenção de afirmar, "vejam, eu não estava lá, mas sei o que aconteceu por que posso provar o que digo com os documentos que utilizo". M ostrar as fontes e inclusive, por vezes, trabalhar com elas na sala de aula, torna-se um meio de dar sustentabilidade ao discurso do professor, no sentido apenas de dar concretude e realidade àquilo sobre o que ele fala. Inserir o documento na sala de aula pode se tornar um modo de submeter a epistemologia da história à didática, na medida em que o documento passa a ser o objeto concreto que vai dar veracidade ao relato histórico. A submissão da epistemologia da história à didática é decorrência da noção essencialista de que as crianças e os adolescentes, em qualquer situação, precisam ter o concreto diante de si para aprender um conceito.

A incômoda e infantil pergunta que ronda a sala de aula e que expõe um critério de verdade corrente na memória coletiva não pode ser respondida simplesmente com o documento. A fonte histórica não pode se prestar a servir fins tão pouco solenes. Sobretudo, 0 uso das fontes na aula de $\mathrm{H}$ istória não pode produzir como 
ef eito a reafirmação do critério de verdade como coincidência entre o relato e a realidade; caso contrário, o objetivo de um ensino de $H$ istória que se coloca na contramão da memória coletiva não se realiza na escola.

Mas, enfim, como se justifica o uso das fontes em sala de (1) aula, rompendo com a noção do documento como prova? Como - se desenredar das afirmações categóricas das crianças e, ao mesmo tempo, desenredar os estudantes das noções de história cristalizadas no nosso cotidiano? 0 uso de fontes históricas deve servir para suspender o caráter de prova que os documentos assumem desde a história tradicional e mostrar às novas gerações a complexidade da construção do conhecimento histórico.

$E$ is a resposta à penúltima pergunta. Cremos que o nosso maior problema é menos ensinar um conteúdo e mais contribuir para criar uma outra memória, que contemple uma outra noção de ciência e de verdade.

0 trabalho com fontes em sala de aula pode ser bastante produtivo, desde que o objetivo seja a complexidade, não a facilitação. 0 problema de certos procedimentos didáticos é que eles procuram arrumar formas de tornar o conhecimento histórico cada vez mais "acessível", submetendo o conhecimento a outros objetivos como, por exemplo, a necessidade de tornar a aula de $\mathrm{H}$ istória mais atraente ou de tornar o distante mais próximo.

A produtividade do uso das fontes está na possibilidade de mostrar às novas gerações a natureza e a especificidade do conhecimento histórico. N osso objetivo, ao ensinar história às novas gerações utilizando fontes, não consiste em ensinar a ler documentos, separá-los por séries, descrever suas regularidades, não se trata de tornar ou querer tornar o estudante um micro-historiador, como se ele tivesse condições intelectuais de fazer o mesmo que os historiadores fazem. Ensinamos os estudantes a ler o relato histórico e ensinamos a ler as representações sobre o passado que circulam na sua sociedade. E nsinar utilizando fontes não quer dizer ensinar a produzir representações através das fontes, mas ensinar como os 
historiadores produzem conhecimento so bre o passado a partir das fontes disponíveis e quais os problemas implicados nessa produção.

Pretendemos, desse modo, ensinar aos estudantes a especificidade da narrativa histórica em relação a outras narrativas do passado, como o cinema, a televisão, a literatura, a música, a maté ria jornalística, dentre outras. 0 u seja, queremos que o estudante se torne alguém capaz de reconhecer na $\mathrm{H}$ istória $\mathrm{o}$ estatuto de uma ciência, com seus limites e suas possibilidades. $\mathrm{N}$ ão precisamos para isso, necessariamente, ensinar o estudante a ler um documento, mas apenas, singelamente, a desconfiar do documento, a olhar pra ele como uma construção do seu tempo e percebêlo como um engenho que uma determinada civilização criou para mostrar às gerações seguintes uma imagem de si mesma.

D esconfiar da fonte não quer dizer atestar sua falsidade, mas olhá-la como um monumento que as sucessivas gerações classificaram, ordenaram e ressignificaram. D esse modo, 0 uso de fontes em sala de aula é profícuo, na medida em que apresenta às novas gerações a complexidade da construção do conhecimento histórico e tira do documento o caráter de prova, desloca o estudante da noção de verdade que utiliza no cotidiano e, sobretudo, permite abordar o relato histórico como uma interpretação.

What can the teaching of history do? On the use of sources in the classroom Abstract: The authors discuss in this paper the use of historical sources in the classroom. This article mainly deals with the purposes and at the same time, the incorporation into the classroom of one of the most important phenomena of contemporary historiography, the so-called "documentary revolution." Thus the concern of the authors is to discuss how history taught in the classroom may become part of the movement of "criticizing the document", and to think of and offer educational alternatives that include the ability to use, in daily history classes, the same sources with which the researchers make up reports of the past. We start from the assumption that the use of sources in the teaching of history may be an appropriate and productive strategy to teach history to individuals who do not wish to become historians, but for whom the knowledge of history can make a difference in understanding the world in which they live.

Keywords: $\mathrm{H}$ istory- Teaching of history - $\mathrm{H}$ istorical sources - $\mathrm{H}$ istorical documents 
O que pode o ensino de história?...

\section{N otas}

${ }^{1} D$ e modo sucinto, a E scola dos A nais designa um movimento de cunho historiográfico, ao qual estão associados nomes como M arc Bloch e Fernando B raudel, dentre outros, combinando elementos deH istória, G eografia e Ciências Sociais na $\infty$ produção do conhecimento. 2002.

${ }^{3}$ LD B, Lei de D iretrizes e Bases, Lei n. 9.394 de 20 de dezembro de 1996.

${ }^{4}$ Referimo-nos aqui à L ei $n-11.645$, de 10 de março de 2008 , que modificou a L ei $n$ o 10.639, de 9 de janeiro de 2003, as duas dispondo sobre conteúdos ligados à história das populações africanas eindígenas.

${ }^{5} \mathrm{~N}$ o artigo "Poderáa H istória ser objetiva", de1995, B lakediscute as dificuldades que ateoriada correspondência coloca para o debate sobre o estatuto científico da H istória. ${ }^{6}$ Trata-se de imagens recorrentes nos livros didáticos de história. E m praticamente to dos os casos, elas são utilizadas para contrabalançar as críticas feitas à I greja Católica e mostram que essa instituição fez algo de positivo durante a I dade M édia que foi manter e preservar a cultura clássica através do paciente trabalho dos monges. 0 ra, verificamos aí uma leitura ainda preconceituosa da I dade M édia, na medida em que supõe que nada de cultura foi produzido no medievo que não fosse cópia do que se produziu na A ntiguidade Clássica.

\section{Referências}

FO U CAULT, M ichel. A arqueologia do saber. Tradução L uiz Felipe Baeta N eves. 3. ed. Rio de Janeiro: ForenseU niversitária, 1987.

LE G O FF, Jacques. A H istória N ova. São Paulo, M artins Fontes, 2005

. H istória eM emória. Tradução Bernardo Leitão et al. Campinas: E ditora daUNICAM P, 2003, p. 29

CHARTIER, Roger. 0 mundo como representação. E studos A vançados, Rio de Janeiro, v. 5, n.11, p. 173-191, 1991.

JE N K IN S, K eith. A H istória repensada. São Paulo, Contexto, 2004.

BLAK E, Christopher. Poderá a H istória ser objetiva? In: G ARD IN E R, Patrick. T eorias da H istória. Lisboa: F undação Calouste G ulbenkian, 1995.

Recebido em 13/08/2008 A provado em 05/ 10/ 2008 